\title{
Vertical Mergers and Competition with a Regulated Bottleneck Monopoly*
}

\author{
Alexander Galetovic ${ }^{\dagger} \quad$ Ricardo Sanhueza $a^{\ddagger}$
}

March 2004

\begin{abstract}
Consider a bottleneck monopoly whose access charge is regulated above marginal cost and provides access to an oligopoly of downstream firms. Should the monopolist be allowed to vertically integrate into the downstream market? For the general run of oligopolistic market structures, we show that a vertical merger (or any set of vertical restraints that eliminates the externalities between the upstream and the downstream firm), will not decrease welfare in most cases.

Vertical integration is irrelevant if the downstream market is perfectly competitive. With an oligopoly, the short- and long-run effects are somewhat different. In the short run consumers and the integrated firm always win, but competitors are hurt because they lose oligopolistic rents. Most of the time welfare increases unless output is redistributed away from efficient competitors toward a very inefficent vertically integrated firm. Finally, if there is free entry, competitors and consumers are indifferent in the long-run and vertical integration always increases welfare.
\end{abstract}

Keywords: access charge, essential input, free entry, network industries, oligopoly, stablity conditions

JEL classification: L12, L22, L51

* We gratefully acknowledge the financial support of Fondecyt under project 1030705 and Telefónica CTC Chile S.A. Galetovic also acknowledges the financial support of the Hewlett Foundation under an institutonal grant to CEA. The opinions are our own and do not represent those of Telefónica CTC Chile S.A. We thank Juan Escobar for very helpful comments and suggestions.

$\dagger$ Centro de Economía Aplicada, Departamento de Ingeniería Industrial, Universidad de Chile. Av. República 701, Santiago, Chile. Tel: +56/2/678 4065; Fax:+56/2/689 7895; email: agaleto@dii.uchile.cl.

$\ddagger$ ESE-Escuela de Negocios, Universidad de los Andes. San Carlos de Apoquindo 2200, Las Condes, Santiago. Tel: +56/2/412 9524. Fax: +56/2/412 9486; E-mail: rsanhueza.ese@uandes.cl. 


\section{Introduction}

Many countries allow owners of regulated bottleneck monopolies to vertically integrate into unregulated downstream markets. ${ }^{1}$ But then the following regulatory dilemma is said to exist: on the one hand, the access charge should be fixed higher than marginal cost, so that the bottleneck monopoly may meet her self-financing constraint; on the other hand, any excess over marginal cost is a mere transfer price for the vertically-integrated affiliate, which is thus granted an "undue" cost advantage. Because of this cost advantage, so the argument runs, the vertically integrated affiliate will adopt strategies that decrease aggregate welfare. ${ }^{2}$ Nevertheless, in this paper we show that under fairly general conditions the "undue" cost advantage claim is suspect: vertical integration never hurts consumers and most of the time increases aggregate welfare.

In our model a bottleneck monopoly sells an essential input, which we call "access," to an downstream oligopoly. We extend the techniques of Farrell and Shapiro (1990) and compare equilibria before and after a "large" vertical merger such that the owner of the bottleneck monopoly acquires one arbitrary downstream firm and then sets her quantity to maximize the sum of the affiliate's profits and those made from selling access. ${ }^{3}$ The post-merger behavior of the acquired firm will be different only because now it maximizes joint profits, hence changes in the equilibrium price, quantities and welfare adequately indicate the effects of vertical integration.

The scope of our analysis can be gleaned from Table 1. One dimension (rows in Table 1) distinguishes between the short- and long-run effect of the merger. In the short run the number of firms in the downstream market is fixed; in the long-run firms enter or exit responding to the merger. At the same time, the affiliate's behavior depends on the intensity of competition in the downstream market (columns in Table 1). Because the exact intensity of downstream competition is seldom an observable, we seek results that are valid for the general run of oligopolistic market structures. Thus we model competition with a quantity-setting conjectural variations model that follows Dixit's (1986). We impose only two restrictions: stability conditions à la Dixit (1986) must hold along firms' reaction functions and market structure must lie between the two extremes of competition and monopoly. In particular, downstream firms need not be symmetric. Table 1 summarizes the main results, which we now discuss.

\footnotetext{
${ }^{1}$ For example, a fixed-phone company who owns the local network may also own a long-distance carrier, an internet provider or a mobile phone company. Or a high-voltage transmission company may also own generation plants or an energy trading company. Or the owner of a gas pipeline may also sell to large users.

${ }^{2}$ For example, this argument was used in 1999 by the Chilean telecom regulator Subtel to justify her decision to price at marginal cost access to the local loop of the dominant local telecom company. In the United States such arguments have been given to oppose the entry of the Bell Operating Companies (BOC) into long distance (see Biglaiser and DeGraba [2001]).

${ }^{3}$ That is, following Mathewson and Winter (1984) and Kühn and Vives (1999), vertical integration is interpreted as any vertical merger or set of vertical restraints that eliminates the externalities between the upstream and the downstream firm.
} 
Perfect competition Vertical integration is irrelevant if the downstream market is perfectly competitive because pre- and post-merger market equilibrium are the same.

The intuition can be appreciated taking a closer look at the central trade off optimized by the vertically-integrated affiliate. On the one hand, her direct cost of access is zero because the access charge, call it $\tau$, is a mere internal transfer price - the "undue" cost advantage - ; this stimulates being more aggressive in the downstream market. On the other hand, being more aggressive may reduce rivals' production and demand for access; this is the perceived opportunity cost borne by the affiliate which is equal to $\tau \times v$, where $v \equiv d Q_{-i} / d q_{i}$ is the conjectural variation: how the aggregate output of firms other than $i, Q_{-i}$, responds to changes in $i$ 's output, $q_{i} \cdot{ }^{4}$

Now when firms are price takers the affiliate perceives that rivals will match her production increments one-by-one with output reductions. Hence $v \equiv-1$, the opportunity cost equals $-\tau$ and nothing changes with vertical integration because the affiliate behaves exactly like the pre-merger firm.

Oligopoly I: short run Consider next the case when the number of firms is fixed and the downstream market is an oligopoly. Now consumers and the integrated firm always win with vertical integration, but competitors are hurt. The intuition is as follows. Because in an oligopoly $v>-1$, the affiliate's marginal cost falls because she perceives that rivals will match her production increases less than one-by-one with output reductions (in fact, her perception may be even that rivals will increase production). Hence $\tau \times v>-\tau$, her post-merger behavior is more aggressive and aggregate output must increase with vertical integration. This erodes the downstream margin and reduces double marginalization - hence consumers are unambiguously better off. Rivals are hurt by lower margins because their oligopolistic rents fall-hardly a reason of concern from a social welfare perspective.

What is the effect on social welfare? We show that when firms' outputs are strategic complements (as in Biglaiser and De Graba [2001] and DeGraba [2003]) welfare must increase: all firms produce more with vertical integration and price-marginal cost margins are positive in an oligopoly. Welfare may, but need not, fall when firms' outputs are strategic substitutes. Essentially, in that case output is redistributed from competitors to the affiliate. If the affiliate is much more inefficient, then the cost increase may compensate the welfare gain of consumers and the higher profits of the affiliate. Thus, inefficient output redistribution may be the only reason why welfare may fall.

Oligopoly II: long run In the long run the equilibrium aggregate quantity and price are the same as before the merger, regardless of market structure downstream. Consequently, vertical integration affects neither consumers nor competitors. The only effect is that the affiliate expands

\footnotetext{
${ }^{4}$ In terms of Armstrong et al. (1996), $-v$ is the homogeneous-good equivalent of the "diversion ratio."
} 
her production, and this is exactly compensated by output reductions by firms that exit at the margin. Because the affiliate's profits increase, welfare unambiguously increases.

Behind this result is a somewhat surprising implication of free entry: in the long run prices are determined only by the long-run average cost of marginal firms and the equilibrium oligopolistic margin is not affected by the merger. We show that this will hold as long as firms' conjecture $v$ does not depend directly on the number of firms in the market - a standard assumption in the IO literature. Essentially, after the vertical merger the affiliate's increase in output is exactly matched by an equivalent reduction of the output of fringe firms, thus leaving the equilibrium price constant.

Vickers (1995) analyzed the regulatory dilemma with a model where a bottleneck monopoly optimally regulated à la Baron-Myerson sells access to a Cournot market with free entry. On the one hand, vertical integration is beneficial because it reduces wasteful duplication of fixed costs brought about by excessive entry; on the other hand, it is costly because the monopolist's benefit of inflating costs is higher. Hence the net effect of vertical integration on welfare is ambiguous and depends on market parameter values.

Contrary to this paper, but like Biglaiser and DeGraba (2001) and De Graba (2003), we take the access charge $\tau$ as exogenously given. One reason to make this assumption is simply practical, as we want to model arbitrary downstream market structures with a tractable model. But in addition, Baron-Myerson regulation requires regulators to be able to fix outputs and make transfers contingent on cost reports. In practice, regulators do not have such instruments available and just fix maximum tariffs. In that setting, monopolists face no trade off when inflating costs and gain the same with higher tariffs whether they are integrated into the downstream market or not. Thus, we believe that as a first pass analysis of regulatory practice it makes sense to assume that $\tau$ is independent of vertical integration. ${ }^{5}$

Biglaiser and DeGraba (2001) and De Graba (2003) also study the regulatory dilemma with models of differentiated products where symmetric downstream firms compete setting prices. In these models prices are naturally strategic complements. Hence, because the vertically integrated affiliate behaves more aggressively, consumers end up better off. Welfare may fall, however, if the change in relative prices diverts enough consumers from their most preferred brand. Of course, this additional source of inefficiency cannot appear in our model because the final product is homogeneous.

Our paper is also related with the literature on optimal access pricing. Laffont and Tirole (1994) and Armstrong et al. (1996) study optimal access charge regulation in a model where the

\footnotetext{
${ }^{5}$ For example, access charges to the local telephone loop are determined by a process that is independent of whether the Bell Operating Companies are allowed into the long-distance market (Biglaiser and DeGraba [2001]). This is also the case in Chile for local telephone companies and electricity distributors.
} 
integrated monopolist competes downstream with a competitive fringe that produces an imperfect substitute. These papers, however, analyze optimal access charge regulation when the price in the downstream market is regulated and the integrated firm. ${ }^{6}$. By contrast, our paper assumes a fully deregulated downstream market and an exogenous access charge. Thus our focus is on the structural question, whether vertical integration into a deregulated downstream market should be allowed, as in Vickers (1995).

A central part of our analysis is to determine the effect of a vertical merger. It turns out that Farrel and Shapiro's (1990) techniques to assess horizontal mergers carry over almost directly, as long as firm $i$ 's best response function depends on competitors actions only through their aggregate output $Q_{i}$. In such a setting, our analysis generalizes theirs in two directions. First, we study the effects of mergers for the general run of oligopolistic market structures, not only when firms compete à la Cournot. Second, allowing entry and exit shows that horizontal mergers are likely to have quite different short- and long-run effects. In particular, with free entry a horizontal merger that reduces costs is always welfare increasing, regardless of market structure.

Before proceeding we call attention to a caveat. We are well aware that, as Dixit (1986, p. 161) notes, the conjectural variations model "is subject to well merited criticism," because "reactions" and "conjectures" have no valid dynamic foundation in a static model. But our aim here is to systematically study the effect of vertical integration, (i) discussing movements in outputs, profits, margins and welfare at the firm and market level; (ii) obtain results that are valid for the general run of market structures with no a priori requirements other than profit maximization and stability.

Section 2 presents the model. Section 3 studies the short-run effects of a merger. Section 4 extends the model and studies exit in response to the merger. Section 5 concludes.

\section{The Model}

\subsection{Model description}

Production A bottleneck monopoly produces an essential input, which we will call "access," at no cost and sells it at a regulated access charge $\tau>0$ to $n$ firms that operate in the downstream market and use it in fixed proportions. Firm $i$ has cost function $c_{i}\left(q_{i}\right)$, where $q_{i} \in[0, \bar{q}]$, with $\bar{q}$ large but finite, is the amount it produces. $Q \equiv \sum_{j=1}^{n} q_{j}$ is the total amount produced in the market and $Q_{-i} \equiv \sum_{j \neq 1}^{n} q_{j}$ is the total amount produced by firms other than $i$. Until section $4, n$ is assumed to be fixed and exogenous. We denote by $\mathbf{c}$ the $1 \times n$ row-vector of cost functions $c_{i}\left(q_{i}\right)$.

\footnotetext{
${ }^{6}$ Armstrong and Vickers (1998) assume a deregulated downstream market, but limit their analysis to a dominant provider with a competitive fringe.
} 
Demand The demand function is $p=p(Q)$ with $p^{\prime}<0$. Also, $D(Q) \equiv p^{-1}(Q)$ and we assume that $p+p^{\prime} Q<0$ (decreasing marginal revenue).

Conjectural variations and strategic interaction in the downstream market To capture the whole range of possible oligopoly outcomes, we use a conjectural variations model based on Dixit (1986). Firm $i$ has the following conjectural variation about how rivals "react" to an increase in $q_{i}$ :

$$
d Q_{-i} / d q_{i}=v\left(q_{i}, Q_{-i}\right)
$$

with partial derivatives $v_{q}$ and $v_{-Q}$. Note that rivals affect $i$ 's conjecture only through $Q_{-i}$; this will be important below. To interpret these conjectural variation, assume that firm $i$ is not vertically integrated. Then her profit function is

$$
\pi_{i}=p(Q) q_{i}-\left[c_{i}\left(q_{i}\right)+\tau q_{i}\right]
$$

and its perceived marginal profit is

$$
\mu_{i}\left(q_{i}, Q_{-i}\right) \equiv d \pi_{i} / d q_{i}=p-\left(c_{i}^{\prime}+\tau\right)+q_{i} p^{\prime}(1+v)
$$

(henceforth we omit function arguments for brevity whenever it does not cause confusion).

Standard models like Cournot, perfect competition and monopolistic collusion are special cases of this general formulation. As a benchmark, note that when $v \equiv 0$ we have Cournot conjectures: when firms optimize, they take $Q_{-i}$ as given. At one extreme, when $v \equiv-1, d \pi_{i} / d q_{i}=$ $p-\left(c_{i}^{\prime}+\tau\right)$ and firms act as if the market is perfectly competitive. At the other extreme, when $v=Q_{-i} / q_{i}$, then $q_{i} p^{\prime}(1+v)=p^{\prime} Q$, and firms collude at the monopoly output.

REMARK We assume that the conjectural variation $v$ is the same for all firms only to avoid an additional subscript. As will become plain below, it is trivial to extend the model to allow for $v_{i} \neq v_{j}$.

It will be convenient to make the following assumption about $v$ :

Assumption 1. For all pairs $(x, X),-1 \leq v(x, X) \leq X / x$.

This assumption simply constrains equilibria in the downstream market to lie between perfect competition and monopoly.

REMARK In terms of Armstrong et al. (1996),- $v$ is the homogeneous-good equivalent of the "diversion ratio." In a differentiated products model where firms compete setting prices (see, for 
example, DeGraba [2003]) this is the ratio of the sum of a firm's cross price effects to its own price effect. In this model it is the ratio of the change in other firms' combined output to a change in a firms own output. When the market is perfectly competitive the diversion ratio is $1: \Delta Q_{-i}=-\Delta q_{i}$; with Cournot conjectures $\Delta Q_{-i}=0$; and with monopolistic collusion $\Delta Q_{-i}=Q_{-i} / q_{i}$-rival output expands with $i$ 's output.

\subsection{Equilibrium in the downstream market}

\subsubsection{Definitions}

Note that each possible model can be described by a tuple $(n, \mathbf{c}, p, v, \tau)$. In what follows it is useful to precisely define equilibrium in the downstream market for model $(n, \mathbf{c}, p, v, \tau)$. Our benchmark is the case with no vertical integration:

Definition 2.1. An equilibrium of the downstream market with no vertical integration in model $(n, \mathbf{c}, p, v, \tau)$ is a price $p^{*}$ and a $1 \times n$ row-vector $\mathbf{q}^{*}$ of firm outputs such that:

(i) Subject to $v\left(q_{i}, Q_{-i}\right)$, firms maximize profits:

$$
q_{i}^{*}=\arg \max \left\{p\left(Q_{-i}^{*}+q_{i}\right) q_{i}-c_{i}\left(q_{i}\right)-\tau q_{i}\right\}
$$

(ii) The market clears:

$$
p^{*}=p\left(Q^{*}\right)
$$

where $Q^{*}=\mathbf{q}^{*} \cdot \mathbf{1}$ ( $\mathbf{1}$ is a $n \times 1$ column-vector of ones).

Next we define an equilibrium in the downstream market when the essential facility vertically integrates. We use the superscript ' $\iota$ ' to denote "vertical integration." Vertical integration consists in the essential facility acquiring one of the $n$ firms in the downstream market, call it firm $m$.

Definition 2.2. An equilibrium of the downstream market with vertical integration in model $(n, \mathbf{c}, p, v, \tau)$ is a price $p^{\iota}$ and a $1 \times n$ row-vector $\mathbf{q}^{\iota}$ of firm outputs such that:

(i) Firms and the monopolist maximize profits:

$$
\begin{gathered}
q_{i}^{\iota}=\arg \max \left\{p\left(Q_{-i}^{\iota}+q_{i}\right) q_{i}-c_{i}\left(q_{i}\right)-\tau q_{i}\right\} . \\
q_{m}^{\iota}=\arg \max \left\{p\left(Q_{-m}^{\iota}+q_{m}\right) q_{m}-c_{m}\left(q_{i}\right)+\tau Q_{-m}^{\iota}\right\} .
\end{gathered}
$$

subject, respectively, to $v\left(q_{i}, Q_{-i}\right)$ and $v\left(q_{m}, Q_{-m}\right)$.

(ii) The market clears:

$$
p^{\iota}=p\left(Q^{\iota}\right)
$$


Note that the objective functions (2.4) and (2.5) differ. On the one hand, the vertically integrated firm does not consider the access charge $\tau$ when expanding production, because from her perspective it is a mere internal transfer fee; this is the justification behind the "undue advantage" claim. On the other hand, the vertically integrated firm benefits from sales of the essential input to competitors; thus, her maximization will be influenced by the effect that she "anticipates," which is captured by her conjectural variation $v\left(q_{m}, Q_{-m}\right)$.

REMARK There is no loss of generality in this way of modeling vertical integration. In particular, suppose that the monopolist acquires $k+1$ downstream firms, $m, m+1, \ldots, m+k$ in model $(n, \mathbf{c}, p, v, \tau)$. Then, we can consider model $\left(n^{\prime}, \mathbf{c}^{\prime}, p, v, \tau\right)$ with $n^{\prime} \equiv n-k$ and $\mathbf{c}^{\prime} \equiv$ $\left(c_{1}, c_{2}, \ldots, c^{m}, c_{m+k+1} \ldots, c_{n}\right)$ with $c^{m}\left(q_{m}\right) \equiv \min \left\{\sum_{j=m}^{m+k} c_{j}\left(q_{j}\right) \mid \sum_{j=m}^{m+k} q_{j}=q_{m}\right\}$ and study the effect of an horizontal merger in model $\left(n^{\prime}, \mathbf{c}^{\prime}, p, v\right)$.

\subsubsection{Stability conditions and some of their implications}

Begin with stability conditions when there is no vertical integration. Then the equilibrium values $\mathbf{q}^{*}$ are defined by $n$ first order conditions

$$
\mu_{i}\left(q_{i}^{*}, Q_{-i}^{*}\right)=p^{*}-\left(c_{i}^{\prime}+\tau\right)+q_{i}^{*} p^{\prime}(1+v)=0 .
$$

The $n$ second-order conditions are

$$
2 p^{\prime}(1+v)+q_{i}^{*} p^{\prime \prime}(1+v)^{2}+q_{i}^{*} p^{\prime}\left(v_{q}+v \cdot v_{-Q}\right)-c_{i}^{\prime \prime}<0 .
$$

Now define

$$
a_{i}\left(q_{i}, Q_{-i}\right) \equiv \partial^{2} \pi_{i} / \partial q_{i}^{2}=p^{\prime}(2+v)+q_{i} p^{\prime \prime}(1+v)+q_{i} p^{\prime} v_{q}-c_{i}^{\prime \prime}
$$

and

$$
b_{i}\left(q_{i}, Q_{-i}\right) \equiv \partial^{2} \pi_{i} / \partial q_{i} \partial Q_{-i}=p^{\prime}+q_{i} p^{\prime \prime}(1+v)+q_{i} p^{\prime} v_{-Q}
$$

That is, $b_{i}$ is the derivative of $i$ 's marginal profit with respect to his competitors' actions. The SOC (2.7) can be now rewritten as $a_{i}+b_{i} v<0$. As Dixit (1986, pp. 117 and 118) shows, necessary conditions for stability are (at the equilibrium point)

$$
a_{i}<0
$$

and that

$$
(-1)^{n} \times \Pi_{i=1}^{n}\left(a_{i}-b_{i}\right) \times\left[1+\sum_{i=1}^{n} \frac{b_{i}}{\left(a_{i}-b_{i}\right)}\right]>0 .
$$


Sufficient conditions for stability are ensured requiring diagonal dominance in the coefficient matrix, i.e.

$$
\left|a_{i}\right|>(n-1)\left|b_{i}\right|
$$

Now it is straightforward to show that if condition (2.10) holds, then for all $i$ :

$$
a_{i}-b_{i}<0
$$

REMARK It can be shown (see Dixit [1986], p. 118) that the slope of the aggregate reaction function facing firm $i$ is

$$
R_{i} \equiv \frac{d Q_{-i}}{d q_{i}}=-\frac{B_{i}}{1+B_{i}}
$$

with $B_{i} \equiv \sum_{j \neq i} b_{j} /\left(a_{j}-b_{j}\right)$. Now since $1+B_{i}>0$ (see Dixit [1986, p. 118]), and $a_{j}-b_{j}<0$, the following follows: if for all firms $i$, marginal profit (2.1) increases with $Q_{-i}$, that is $b_{i}>0$ for all $i$, $R_{i}>0$ for all $i$. Thus, we have a model with strategic complements in the standard terminology of Bulow et al. (1985). If, on the other hand, marginal profit (2.1) falls with $Q_{-i}$, that is $b_{i}<0$ for all $i, R_{i}<0$ for all $i$ and we have a model with strategic substitutes. Below we will repeatedly use this taxonomy.

Now with vertical integration stability conditions must be slightly modified to account for the change in $m$ 's objective function. Her FOC is

$$
\mu_{m}^{\iota}\left(q_{m}^{\iota}, Q_{-m}^{\iota}\right)=p^{\iota}-\left(c_{m}^{\prime}+\tau\right)+q_{m}^{\iota} p^{\prime}(1+v)+\tau(1+v)=0
$$

with SOC

$$
2 p^{\prime}(1+v)+q_{m}^{\iota} p^{\prime \prime}(1+v)^{2}+q_{m}^{\iota} p^{\prime}\left(v_{q}+v \cdot v_{-Q}\right)-c_{m}^{\prime \prime}+\tau\left(v_{q}+v \cdot v_{-Q}\right)<0 .
$$

Now it can be easily shown that

$$
a_{m}^{\iota}\left(q_{m}, Q_{-m}\right)=a_{m}+\tau v_{q}
$$

and

$$
b_{m}^{\iota}\left(q_{m}, Q_{-m}\right)=b_{m}+\tau v_{-Q} .
$$

Hence, $a_{m}^{\iota}+b_{m}^{\iota} v=a_{m}+b_{m} v+\tau\left(v_{q}+v \cdot v_{-Q}\right)<0$ is firm's $m$ SOC and stability conditions are as (2.8), (2.9) and (2.10) but substituting $a_{m}^{\iota}$ for $a_{m}$ and $b_{m}^{\iota}$ for $b_{m}$.

REMARK With Cournot conjectures $v \equiv 0$. Thus $v_{q}=v_{-Q}=0$ and $a_{m}^{\iota}=a_{m}$ and $b_{m}^{\iota}=b_{m}$. Similarly, with perfect competition $v \equiv-1$. 
The following assumption indicates the class of models for which our analysis applies.

Assumption 2. We consider the set of models ( $n, \mathbf{c}, p, v, \tau)$ such that: (i) they have at least one equilibrium without vertical integration and one equilibrium with vertical integration; (ii) (2.8), (2.9) and (2.10), and their equivalents when firm $m$ is vertically integrated, hold for all pairs $\left(q_{i}, Q_{-i}\right)$ along $i$ 's reaction curve for all firms $i$. Call this set of models $\mathcal{M}$.

Assumption 1 implies the following result which will be useful in what follows:

Lemma 2.3. Each model $(n, \mathbf{c}, p, v, \tau) \in \mathcal{M}$ has one and only one equilibrium without vertical integration, and one and only one equilibrium with vertical integration.

Proof. See Escobar and Galetovic (2004) for the detailed proof. Here we present a shorter version.

Existence is by assumption. Proving uniqueness amounts to show that the hypothesis of the Poincaré-Hopf index theorem hold at any equilibrium point. This theorem implies that if $\mathrm{g}: A \rightarrow \mathrm{IR}^{n}$, where $A$ is a compact cube in $\mathrm{IR}^{n}$ and the determinant of $D(-\mathbf{g}(a))>0$ whenever $\mathbf{g}(a)=0$, then there is a unique solution to $\mathbf{g}(a)=0 .^{7}$

Now here $\mathbf{g}(\mathbf{q}) \equiv\left[\mu_{1}\left(q_{1}, Q_{-i}\right), \ldots, \mu_{n}\left(q_{n}, Q_{-n}\right)\right]^{\prime}$ and

$$
D[-\mathbf{g}(a)]=(-1) \times\left[\begin{array}{cccc}
a_{1} & b_{1} & \ldots & b_{1} \\
b_{2} & a_{2} & \ldots & b_{2} \\
\vdots & & \ddots & \vdots \\
b_{n} & b_{n} & \ldots & a_{n}
\end{array}\right]
$$

The determinant of $D[-\mathbf{g}(a)]$ equals (see Seade [1983])

$$
(-1)^{n} \times \Pi_{i=1}^{n}\left(a_{i}-b_{i}\right) \times\left[1+\sum_{i=1}^{n} \frac{b_{i}}{a_{i}-b_{i}}\right]
$$

which is strictly positive by stability condition (2.9). An analogous argument shows that the equilibrium with vertical integration is unique.

\subsubsection{The competitive response of independent firms}

Almost by definition, a merger's effect on quantities is "large," but comparative static exercises are valid only for small changes. In this section we show how to use these conditions to explore the effects of "large" mergers.

\footnotetext{
${ }^{7}$ See Vives (1999, p. 48).
} 
The following result, which generalizes a result by Farrel and Shapiro (1990) obtained for Cournot oligopoly, summarizes the effect of an increase in output on competitors and thus aggregate market outcomes.

Lemma 2.4. Consider an exogenous change in firm $m$ 's output $\Delta q_{m}>0$ in model $(n, \mathbf{c}, p, v, \tau) \in$ $\mathcal{M}$, and let the other firms' outputs adjust to re-establish an equilibrium among themselves; call $\Delta Q \equiv \Delta q_{m}+\sum_{i \neq m} \Delta q_{i}$ the resulting change in aggregate output. Then (i) $\Delta Q>0$, i.e. aggregate output moves in the same direction as $q_{m}$; (ii) if firms' reaction curves slope downwards over the whole relevant range, (i.e. firms' outputs are strategic substitutes) then $\Delta Q<\Delta q_{m}$ and $\Delta q_{i}<0$ for all $i$ other than $m$; (iii) if firms' reaction curves slope upwards over the whole relevant range (i.e. firms' outputs are strategic complements), then $\Delta Q>\Delta q_{m}$ and $\Delta q_{i}>0$ for all $i$ other than $m$; (iv) profits fall for all firms $i \neq m$.

Proof. Since any discrete change $\Delta q_{m}$ can be decomposed as the integral sum of infinitesimal changes, it is enough to prove the Lemma for an infinitesimal change $d q_{m}$ whenever signs do not change. For part (i), if $d Q$ has the same sign as $d q_{m}$, then $\Delta Q$ has the same sign as $\Delta q_{m}$; for part (ii) if $0<d Q / d q_{m}<1$, then $0<\Delta Q / \Delta q_{m}<1$ and if $d q_{i}<0$ then $\Delta q_{i}<0$; for part (iii), if $d Q / d q_{m}>1$, then $\Delta Q / \Delta q_{m}>1$ and if $d q_{i}<0$ then $\Delta q_{i}<0$; for part (iv), if $d \pi_{i}<0$, then $\Delta \pi_{i}<0$.

Now by the definition of the aggregate reaction function facing firm $m$ we have that $d Q_{-m}=$ $R_{m} d q_{m}$. Since $d Q \equiv d q_{m}+d Q_{-m}$, it follows that $d Q=\left(1+R_{m}\right) d q_{m}$. Definition (2.12) implies that

$$
d Q=\frac{1}{1+B_{m}} d q_{m}
$$

Part (i) follows from noting that $1+B_{m}>0$. Now if firms' outputs are strategic substitutes, then $B_{m}>0$, and $d Q<d q_{m}$; this establishes that aggregate output increases but less than $\Delta q_{m}$. If outputs are strategic complements, $B_{m}<0$ and $d Q>d q_{m}$; this establishes that aggregate output increases by more than $\Delta q_{m}$.

To compute the effect on individual outputs, note that equilibrium requires that

$$
\left(a_{i}-b_{i}\right) d q_{i}+b_{i} d Q=0
$$

for all firms $i$. Solving for $d q_{i}$, and adding up for all $i$ yields $d Q=-B_{m} d Q+d q_{m}$, hence $d Q=$ $d q_{m} /\left(1+B_{m}\right)$. Substituting back into (2.14) yields

$$
d q_{i}=-\frac{b_{i}}{a_{i}-b_{i}} \times \frac{1}{1+B_{m}} \times d q_{m}
$$

which has the sign of $b_{i}$ : it is always negative if outputs are strategic substitutes, always positive 
if they are strategic complements. This establishes parts (ii) and (iii).

To prove part (iv) note that $d \pi_{i}=q_{i} p^{\prime}\left[d Q-(1+v) d q_{i}\right]$. Substituting for $d Q$ from $(2.13)$ and $d q_{i}$ from $(2.15)$

$$
d \pi_{i}=\frac{q_{i} p^{\prime}}{1+B_{m}} \times \frac{a_{i}+b_{i} v}{a_{i}-b_{i}} \times d q_{m} .
$$

The sign of the first fraction is obviously negative; the numerator of the second fraction is the second-order condition, and (2.11) implies that the second fraction is positive. This completes the proof.

The lemma states several important facts. To begin, provided stability conditions are met, an infinitesimal change in the output of oligopolist $m$ will result in an infinitesimal change in aggregate output of the same sign, regardless of the type of strategic interaction - in particular, the result is valid even when reactions curves change slope in the trajectory. Similarly, profits of rivals will fall. Second, output of competitors unambiguously falls for strategic substitutes, and increases for complements.

REMARK Note that firm $m$ need not behave optimally for Lemma 2.4 to hold. This just indicates that a change in firm $m$ 's circumstances will affect the equilibrium of competitors only through $q_{m}$. For this reason, the lemma is useful to analyze the effects of any change wrought by vertical integration that affects m's output - e.g. economies or diseconomies of scope, predation. Moreover, Lemma 2.4 extends Farrel and Shapiro's (1990) results to arbitrary oligopolistic market structures.

REMARK Note that in the proof of Lemma $2.4 a_{i}, b_{i}$ and $B_{m}$ are the same with and without vertical integration. Hence the proof is valid for changes in $m$ 's output both with and without vertical integration.

\section{The effect of a vertical merger}

We are now ready to study vertical mergers. Consider a model $(n, \mathbf{c}, p, v, \tau) \in \mathcal{M}$ and compute the equilibrium $\left(p^{*}, \mathbf{q}^{*}\right)$ in the downstream market with no vertical integration. Then assume that firm $m$ vertically integrates, and compute the equilibrium $\left(p^{\iota}, \mathbf{q}^{\iota}\right)$ in the downstream market with vertical integration. How does the equilibrium change after the vertical merger? Section 3.1 studies the effect of the vertical merger on market equilibria. Section 3.2 analyzes how aggregate welfare changes and is redistributed among consumers, the vertically integrated firm and competitors. 


\subsection{The effect on downstream market equilibrium}

To assess the market effect of a vertical merger, we first determine the equilibrium effect on $m$ 's output. Then we can use Lemma 2.4 to assess the equilibrium response of non-integrated firms.

For $i \neq m$, the optimization problem with vertical integration is the same as without vertical integration. By contrast, for firm $m$, the objective is now to choose $q_{m}$ to maximize the sum of profits by the essential facility and the vertically integrated downstream firm, viz.

$$
p q_{m}-c_{m}-\tau\left(q_{m}-\tau Q_{m}\right)=p q_{m}-c_{m}+\tau Q_{-m} .
$$

As the left-hand side of (3.1) indicates, the ceteris paribus effect of the merger is akin to reducing the cost of the vertically integrated firm. Alternatively, one can consolidate profits thus eliminating the internal transfer between the monopoly and the affiliate; the result is the right-hand side of (3.1).

The first two terms of the right-hand side $\left(p q_{m}-c_{m}\right)$ are usually highlighted by those who argue that vertical mergers confer an "undue advantage" to the affiliate. Being just an internal transfer price, the cost term $\tau q_{m}$ drops with vertical integration. Nevertheless, this argument ignores that production by rivals raises $m$ 's profit because they pay the access charge $\tau$. Thus, if $Q_{-m}$ falls, the essential facility bears an opportunity cost. To assess the magnitude of the opportunity cost, note that the pre-merger marginal profit function of firm $m$ is

$$
d \pi_{m} / d q_{m}=p+q_{m} p^{\prime}(1+v)-\left(c_{m}^{\prime}+\tau\right),
$$

while the post-merger function is

$$
\begin{aligned}
d \pi_{m}^{\iota} / d q_{m} & =p+q_{m} p^{\prime}(1+v)-c_{m}^{\prime}+\tau v \\
& =p+q_{m} p^{\prime}(1+v)-\left(c_{m}^{\prime}+\tau\right)+\tau(1+v)
\end{aligned}
$$

The following result follows immediately from comparing both marginal profit functions when $v \equiv-1$ :

Proposition 3.1. If the downstream market is perfectly competitive $(v \equiv-1)$ then $\left(p^{\iota}, \mathbf{q}^{\iota}\right)=$ $\left(p^{*}, \mathbf{q}^{*}\right)$ is an equilibrium of the downstream market with vertical integration.

Proof. If $v \equiv-1$ then $\left(p^{*}, \mathbf{q}^{*}\right)$ solves the system of $n$ FOC in the model with vertical integration, $\mu_{i}\left(q_{i}^{*}, Q_{-i}^{*}\right)=0$. The result follows from uniqueness.

The intuition is as follows. If the downstream market is perfectly competitive, then $p$ is given, and any increase in the merged firm's output must be compensated one-by-one by a decrease in 
the output of competitors. Thus, $q_{m}^{*}$ is also optimal.

Now if $v>-1$ and competition is imperfect, the cost of access for the affiliate is in fact smaller:

Proposition 3.2. If the downstream market is imperfectly competitive, the affiliate's opportunity cost of access is smaller than $\tau$.

Proof. For any pair $\left(q_{m}, Q_{-m}\right)$

$$
p+q_{m} p^{\prime}(1+v)-\left(c_{m}^{\prime}+\tau\right)+\tau(1+v)>p+q_{m} p^{\prime}(1+v)-\left(c_{m}^{\prime}+\tau\right)
$$

because $v>-1$.

Proposition 3.2 would seem to confirm the fears of an "undue advantage" of the integrated monopolist. But as we will show next, the cost advantage always benefits consumers and it is likely to increase welfare. To get that result, we first show that $m$ 's output rises after the vertical merger.

Lemma 3.3. $q_{m}^{\iota}>q_{m}^{*}$.

Proof. Suppose, by way of contradiction, that $q_{m}^{\iota} \leq q_{m}^{*}$. We examine how $m$ 's marginal profit function

$$
\mu_{m}^{\iota}\left[q_{m}, Q_{-m}\left(q_{m}\right)\right]=p+q_{m} p^{\prime}(1+v)-c_{m}^{\prime}+\tau v,
$$

with $Q_{-m}\left(q_{m}\right)$ the profit-maximizing response of firms $i \neq m$, as $q_{m}$ changes. The contradiction will be established by showing that $\mu_{m}^{\iota}\left[q_{m}, Q_{-m}\left(q_{m}\right)\right]$ increases as $q_{m}$ falls. Hence, one cannot find $q_{m} \leq q_{m}^{*}$ such that $\mu_{m}^{\iota}\left[q_{m}, Q_{-m}\left(q_{m}\right)\right]=0$ and then $\mu_{m}^{\iota}\left[q_{m}^{*}, Q_{-m}\left(q_{m}^{*}\right)\right]>0$.

Now totally differentiating (3.2) and after some algebraic manipulation,

$$
\frac{\partial \mu_{m}^{\iota}}{\partial q_{m}}+\frac{\partial \mu_{m}^{\iota}}{\partial Q_{-m}} \frac{d Q_{-m}}{d q_{m}}=a_{m}^{\iota}-b_{m}^{\iota} R_{m}<0
$$

where the inequality follows by noting that (i) $a_{m}^{\iota}<0$, by stability; and (ii)

$$
\left|a_{m}^{\iota}\right|>(n-1)\left|b_{m}^{\iota}\right|>R_{m}\left|b_{m}^{\iota}\right|
$$

where the first inequality follows from stability and the second from Dixit (1986, p. 119). Hence $\mu_{m}^{\iota}\left[q_{m}, Q_{-m}\left(q_{m}\right)\right]>\mu_{m}^{\iota}\left[q_{m}^{*}, Q_{-m}\left(q_{m}^{*}\right)\right]>0$ for all $q_{m} \leq q_{m}^{*}$.

We are now ready to state and prove the main result in this paper which characterizes vertical integration with an oligopolistic downstream market: 
Proposition 3.4. Fix model $(n, \mathbf{c}, p, v, \tau) \in \mathcal{M}$, with $v>-1$. Let $\left(p^{*}, \mathbf{q}^{*}\right)$ be the equilibrium in the downstream market with no vertical integration and $\left(p^{\iota}, \mathbf{q}^{\iota}\right)$ the corresponding equilibrium when firm $m$ vertically integrates. Also, let $\boldsymbol{\pi}^{\iota}$ and $\boldsymbol{\pi}^{*}$ be the corresponding vectors of profits. Then: (i) $p^{\iota}<p^{*}, Q^{\iota}>Q^{*}$ and $\pi_{i}^{\iota}<\pi_{i}^{*}$ for all $i \neq m$; (ii) if firm's outputs are strategic substitutes, then $q_{i}^{\iota}<q_{i}^{*}$ for all $i \neq m$; (iii) if firm's outputs are strategic complements, then $q_{i}^{\iota}>q_{i}^{*}$ for all $i \neq m$.

Proof. The proof is a straightforward implication of Lemmas 2.4 and 3.3.

Thus a vertical merger always benefits consumers. ${ }^{8}$ The intuition is quite simple. Having a cost advantage, the affiliate expands production and reduces the distortion due to oligopolistic competition. At the same time, the vertical merger hurts competitors because the equilibrium price falls, which would seem to corroborate the claim of an "undue" advantage. Nevertheless, competitors are hurt only because they lose rents that originate in the exercise of market powerhardly a reason to be concerned from a social welfare perspective.

\subsection{Welfare}

We can now analyze the welfare impact of a vertical merger using the technique developed by Farrell and Shapiro (1990). Most of the time a vertical merger will affect production discretely. But any discrete change in welfare can be decomposed as a sum of infinitesimal changes. Moreover, we have seen that the response of firms $i \neq m$ depends only on the change in $q_{m}$. Hence, the change in welfare $\Delta W$ of a discrete change $\Delta q_{m}$ is equal to

$$
\Delta W=\int_{q_{m}^{*}}^{q_{m}^{\iota}} \frac{d W}{d q_{m}} d q_{m}
$$

where $q_{m}^{*}$ is $m$ 's pre-merger output, $q_{m}^{\iota}$ is $m$ 's post merger output and the integrand is evaluated assuming that firms $i \neq i$ behave optimally given $v$ and $q_{m}$. Thus, as long as we can sign $\frac{d W}{d q_{m}}$ all along the path, we can obtain the welfare effect of a merger that discretely rises $m$ 's output.

Hence consider first the welfare effect of a small increase in $m$ 's output, $d q_{m}$. Since the gross benefit of output is measured at price $p$, we have

$$
\begin{aligned}
d W & =p d q_{m}-d c_{m}+\sum_{i \neq m}\left(p-c_{i}^{\prime}\right) d q_{i} \\
& =\left(p-c_{m}^{\prime}\right) d q_{m}+\sum_{i \neq m}\left(p-c_{i}^{\prime}\right) d q_{i}
\end{aligned}
$$

Now with strategic complements all firms expand for any $q_{m}$. Hence welfare must rise:

\footnotetext{
${ }^{8}$ Of course, we are assuming that there is no sabotage. See the discussion in the conclusion.
} 
Result 3.5. If outputs are strategic complements then $\Delta W>0$ when $m$ 's output expands.

Things are not straightforward when the production of rivals falls and production is redistributed towards the merged firm, because the reallocation may be inefficient. To see this, rewrite $d W$ as

$$
\left(p-c_{m}^{\prime}\right) d Q+\sum_{i \neq m}\left(c_{m}^{\prime}-c_{i}^{\prime}\right) d q_{i}
$$

The first term is the increase in welfare because aggregate output rises with $m$ 's. The second term is the effect on welfare of the redistribution of output towards $m$.

In any case, it is apparent that if $m$ 's marginal cost is not higher than any of the other firms, welfare must rise because the redistribution of output reduces total costs:

Result 3.6. If $m$ 's marginal cost is the smallest, then $\Delta W>0$ when $m$ 's output expands.

It follows that in the special but standard case when marginal costs are constant and the same for all firms, welfare unambiguously rises with a vertical merger. It is also clear that a necessary (but not sufficient) condition for welfare to fall with the vertical merger is that output must be redistributed towards a less efficient merged firm.

To analyze the case when $m$ is not the most efficient firm, rewrite (3.3) as follows. First, note that $p-c_{i}^{\prime}=\tau-q_{i} p^{\prime}(1+v)$ and $d q_{i}=-\frac{b_{i}}{a_{i}-b_{i}} d Q$. Adding and substracting $q_{m} d p$ and making the appropriate substitutions we have that

$$
\begin{aligned}
d W & =\left(p d q_{m}+q_{m} d p-d c_{m}\right)-q_{m} d p-\sum_{i \neq m}\left[\tau-q_{i} p^{\prime}(1+v)\right] \frac{b_{i}}{a_{i}-b_{i}} d Q \\
& =\left(d \pi_{m}+\tau R_{m} d Q\right)-\left(s_{m}-\sum_{i \neq m} \lambda_{i} s_{i}\right) Q p^{\prime} d Q
\end{aligned}
$$

where $s_{i}$ is firm $i$ 's market share and $\lambda_{i} \equiv(1+v) \frac{b_{i}}{a_{i}-b_{i}}$.

The first parenthesis is the change in profits of the merged downstream firm, which is clearly positive. Following Farrell and Shapiro (1990), we can call the second term the merger's "external effect," the sum of the changes in consumer surplus and profits of firms other than $m$. It follows that a necessary condition for a merger to decrease welfare is $s_{m}-\sum_{i \neq m} \lambda_{i} s_{i}<0$; conversely, a sufficient condition for a merger to be welfare improving when outputs are strategic substitutes is that $s_{m}-\sum_{i \neq m} \lambda_{i} s_{i} \geq 0$ all along the integration path.

We might examine which conditions on demand, cost and reaction functions are sufficient for $s_{m}-\sum_{i \neq m} \lambda_{i} s_{i} \geq 0$, but we would get further than Farrell and Shapiro's (1990) Proposition 5. Essentially, the problem is that third order effects inevitably appear, and they cannot be ignored because a merger is lumpy. Thus sufficient conditions can be obtained only restricting the sign of the third derivatives of demand, cost and reaction functions. The only "general" lesson that we can extract is that a vertical merger hurts welfare only if there occurs a significant output redistribution towards an inefficient merged firm. 


\section{Entry and long-run equilibrium}

So far our analysis has assumed that the number of firms with or without vertical integration is the same. But because profits fall with vertical integration, one may expect firms to exit in a long-run equilibrium. In this section we compare equilibria with and without vertical integration allowing free entry. The somewhat surprising result is that under "standard" assumptions vertical integration does not affect prices and is unambiguously welfare increasing.

\subsection{Modeling exit}

To model exit, one must assume something about the firms that are "at the margin." A standard assumption is that there is a fringe of identical firms that enter or exit depending on the long-run equilibrium price. Thus add to any model $(n, \mathbf{c}, p, v, \tau) \in \mathcal{M}$ a fringe of identical firms with cost function $k+c_{f}(q)$, where $k$ is a fixed cost which is independent of $q$ and $c_{f}^{\prime}>0$. We assume that $k+c_{f}(q) \geq c_{i}(q)$ for all $q \geq 0$ and for all $i \in\{1,2, \ldots, n\}$ - that is, firms in the fringe produce at a cost at least as high as firms in model $(n, \mathbf{c}, p, v, \tau)$. Also, for simplicity we assume that the number of fringe firms active in equilibrium, $f$, is continuous. ${ }^{9}$ Call these set of model $\mathcal{M}^{f}$.

The timing is as follows. In the first stage of the game, firms decide whether they enter. In the second stage, they compete. We first define an equilibrium with entry and then state the main result of this section.

\subsection{Long-run equilibrium in the downstream market}

Definitions As before, it is useful to define equilibrium:

Definition 4.1. An equilibrium of the downstream market with free entry and no vertical integration in model $(n, \mathbf{c}, p, v, \tau)$ is a price $p^{*}$, a $1 \times n$ row-vector $\mathbf{q}^{*}$ of firm outputs and numbers $\left(q_{f}^{*}, f^{*}\right)$ such that:

(i) Subject to $v\left(q_{i}, Q_{-i}\right)$, firms maximize profits:

$$
q_{j}^{*}=\arg \max \left\{p\left(Q_{-i}^{*}+q_{i}\right) q_{i}-c_{i}\left(q_{i}\right)-\tau q_{i}\right\} .
$$

(ii) Each active fringe firm makes zero profits:

$$
p^{*} q_{f}^{*}-k-c_{f}\left(q_{f}^{*}\right)-\tau q_{f}^{*}=0 .
$$

\footnotetext{
${ }^{9}$ Seade (1980) showed that continuity at the margin entails no loss of generality. If the number of fringe firms $f$ is continuous, then restrict attention to integer values of this variable. Then if $\xi$ is any dependent variable defined on $f$, its change when one additional discrete firm enters equals $\Delta \xi=\int_{f}^{f+1} \xi^{\prime}(u) d u$. It is clear that $(\operatorname{sign} \Delta \xi)=\left[\operatorname{sign} \xi^{\prime}(u)\right]$ whenever the latter sign does not change in the interval $(f, f+1)$. Thus, the significant assumption one makes is that the sign of $\xi^{\prime}(u)$ does not change, which will hold if stability conditions do.
} 
(iii) The market clears:

$$
D\left(p^{*}\right)=Q^{*}=\mathbf{q}^{*} \cdot \mathbf{1}+f^{*} q_{f}^{*}
$$

Next we define an equilibrium in the downstream market when the essential facility vertically integrates.

Definition 4.2. An equilibrium of the downstream market with free entry and vertical integration in model $(n, \mathbf{c}, p, v, \tau)$ is a price $p^{\iota}$, a $1 \times n$ row-vector $\mathbf{q}^{\iota}$ of firm outputs and numbers $\left(q_{f}^{\iota}, f^{\iota}\right)$ such that:

(i) Subject to $v\left(q_{i}, Q_{-i}\right)$, firms and the monopolist maximize profits:

$$
\begin{gathered}
q_{i}^{\iota}=\arg \max \left\{p\left(Q_{-i}^{\iota}+q_{i}\right) q_{i}-c_{i}\left(q_{i}\right)-\tau q_{i}\right\} . \\
q_{m}^{\iota}=\arg \max \left\{p\left(Q_{-m}^{\iota}+q_{m}\right) q_{m}-c_{m}\left(q_{i}\right)-\tau\left(Q_{m}-q_{m}\right)\right\} .
\end{gathered}
$$

(ii) Each active fringe firm makes zero profits:

$$
p^{\iota} q_{f}^{\iota}-k-c_{f}\left(q_{f}^{\iota}\right)-\tau q_{f}^{\iota}=0
$$

(iii) The market clears:

$$
D\left(p^{\iota}\right)=Q^{\iota}=\mathbf{q}^{\iota} \cdot \mathbf{1}+f^{\iota} q_{f}^{\iota}
$$

REMARK Continuity in $f$ allows the convenience of defining the fringe's entry condition as a strict zero profit condition.

The following additional technical assumption is made to ensure that in any equilibrium with or without vertical integration, $f>0$ :

Assumption 3. Consider the subset of models in $\mathcal{M}^{f}$ such that $v \equiv-1$. For this subset, $f>0$ in all equilibria with vertical integration.

Assumption 3 is sufficient because in models without entry the equilibrium price is lowest when the downstream market is perfectly competitive. If that price is sufficient to cover the minimum average cost of a fringe firm, entry is profitable at higher prices a fortitiori. We make this assumption because, as Seade (1980) argued, "entry" has no straightforward meaning if fringe firms are not homogeneous. 
The long-run effect of vertical integration We now state and prove the main result of this section. It says that vertical integration does not affect the equilibrium price if there is free entry because $m$ 's expansion of output is exactly compensated by an equivalent exit of fringe firms.

Proposition 4.3. Let $\left(p^{*}, \mathbf{q}^{*}, q_{f}^{*}, f^{*}\right)$ be an equilibrium of the downstream market with free entry and no vertical integration in model $(n, \mathbf{c}, p, v, \tau)$. Then $\left(p^{*}, \mathbf{q}^{\iota}, q_{f}^{*}, f^{\iota}\right)$ is an equilibrium of the downstream market with free entry and vertical integration with (i) $q_{i}^{\iota}=q_{i}^{*}$ for all $i \neq m$; (ii) $q_{f}^{\iota}=q_{f}^{*}$; (iii) $q_{m}^{\iota}-q_{m}^{*}=\left(f^{*}-f^{\iota}\right) q_{f}^{*}>0$; (iv) $q_{m}^{\iota} \in\left(q_{m}^{*}, q_{m}^{*}+f^{*} q_{f}^{*}\right)$.

Proof. Uniqueness implies that it suffices to show that there exists such $\left(p^{*}, \mathbf{q}^{\iota}, q_{f}^{*}, f^{\iota}\right)$ that satisfies the relevant FOC.

Now (i)-(iv) hold then $Q^{\iota}=Q^{*}$ and $Q_{-i}^{\iota}=Q_{-i}^{*}$ for all active $i \neq m$. It follows that $q_{i}^{*}=\arg \max \left\{p\left(Q_{-i}^{*}+q_{i}\right) q_{i}-c_{i}\left(q_{i}\right)-\tau q_{i}\right\}$ for all $i \neq m$. Moreover, all active fringe firms make zero profits and the market clears. It remains to be shown that there exists $q_{m}^{\iota} \in\left(q_{m}^{*}, q_{m}^{*}+f^{*} q_{f}^{*}\right)$ such that

$$
p^{*}\left(Q^{*}\right)+q_{m}^{\iota} p^{\prime}\left(Q^{*}\right)(1+v)-c_{m}^{\prime}\left(q_{m}^{\iota}\right)+\tau v=0
$$

with $v$ evaluated at $\left(q_{m}^{\iota}, Q^{*}-q_{m}^{\iota}\right)$.

To prove this define

$$
\phi\left(q_{m}\right) \equiv p\left(Q^{*}\right)+q_{m} p^{\prime}\left(Q^{*}\right)(1+v)-c_{m}^{\prime}\left(q_{m}\right)+\tau v
$$

and

$$
\psi\left(q_{m}\right) \equiv \phi\left(q_{m}\right)-\tau(1+v)
$$

with $v$ evaluated at $\left(q_{m}, Q^{*}-q_{m}\right)$. Note that $\psi\left(q_{m}^{*}\right)=0$ and $\phi\left(q_{m}\right)>\psi\left(q_{m}\right)$ for all $\left(q_{m}, Q^{*}-q_{m}\right)$. Thus, $\phi\left(q_{m}^{*}\right)>0$; moreover, $\phi\left(Q^{*}\right)<0 .{ }^{10}$ It follows that there exists at least one $\widetilde{q}_{m}$ such that $\phi\left(\widetilde{q}_{m}\right)=0$. But uniqueness implies that $\widetilde{q}_{m} \equiv q_{m}^{\iota}$. By the second-order condition we have that both $\mu_{m}$ and $\mu_{m}^{\iota}$ are downward sloping at the optimum, hence $q_{m}^{\iota}>q_{m}^{*}$. Last, $f^{\iota}=\left[q_{m}^{\iota}+\sum_{i \neq m} q_{i}^{*}\right] / q_{f}^{*}>$ 0 follows from Assumption 3.

It is well known that with perfect competition the long-run equilibrium price is determined only by the minimum long-run average cost of entrants and is independent of market concentration

\footnotetext{
${ }^{10}$ The proof is as follows. Assumption 1 implies that $\max \left\{v\left(Q^{*}, 0\right)\right\}=0 / Q^{*}=0$. Hence $v\left(Q^{*}, 0\right) \in(-1,0]$. Now

$$
\phi\left(Q^{*}\right)=p\left(Q^{*}\right)+Q^{*} p^{\prime}\left(Q^{*}\right)-c_{m}^{\prime}\left(Q^{*}\right)+v\left[\tau+Q^{*} p^{\prime}\left(Q^{*}\right)\right] .
$$
}

Since $p\left(Q^{*}\right)+Q^{*} p^{\prime}\left(Q^{*}\right)$ by assumption, this is clearly negative if either $v=0$ or $\tau+Q^{*} p^{\prime}\left(Q^{*}\right)>0$. If $\left.\tau+Q^{*} p^{\prime}\left(Q^{*}\right)\right]<0$, on the other hand, $\phi\left(Q^{*}\right)$ cannot be greater than

$$
p\left(Q^{*}\right)+Q^{*} p^{\prime}\left(Q^{*}\right)-c_{m}^{\prime}\left(Q^{*}\right)-\left[\tau+Q^{*} p^{\prime}\left(Q^{*}\right)\right],
$$

which is at most 0 if all output is optimally produced by one firm when the market is perfectly competitive. 
(see Bustos and Galetovic [2003] for a proof); to some extent, Proposition 4.3 extends this result to arbitrary market structures. In other words, the merger does not affect the equilibrium oligopolistic margin, regardless of the intensity of competition. ${ }^{11}$ This result may seem surprising, because standard intuition and formal analysis show that prices tend to fall with entry when the market is imperfectly competitive (see, for example, Seade [1980] and Mankiw and Whinston [1986]). What explains this seeming paradox?

The intuition can be appreciated with the help of Figure 1. Because fringe firms must make zero profits in equilibrium, $p^{*}$ must equal the average cost of a fringe firm. At the same time, the price-marginal cost margin

$$
p^{*}-c_{f}^{\prime}\left(q_{f}^{*}\right)=q_{f}^{*} p^{\prime}\left(Q^{*}\right)\left[1+v\left(q_{f}^{*}, Q_{-f}^{*}\right)\right]
$$

is determined by $v$ and increases as the intensity of competition falls. When the market is perfectly competitive $v=-1$, the margin is zero and the standard result follows: in the long-run the equilibrium price equals the minimum average cost. On the other hand, in an oligopoly $p^{*}$ must be equal to average cost and, in addition, yield a price-marginal cost margin consistent with $v$. Because $v\left(q_{f}^{*}, Q_{-f}^{*}\right)$ is a function of the number of firms only through $Q_{-f}^{*}$, which vertical integration leaves unchanged, and $p^{\prime}$ is a function only of $Q^{*}$, the equilibrium margin of fringe firms does not change with the merger. Hence, neither does the long-run equilibrium price. More generally, any change that affects the composition of output among inframarginal firms will affect the number of fringe firms, but not the equilibrium price. Thus, it is essentially the assumption that the conjectural variation is independent of the number of firms that underlies the result.

Of course, one might argue that changes in $n$ affect the type of competition - that is, $v$ is a function of $n$ directly. But we should mention that common practice among IO economists is to model as if $n$ does not affect $v$ except through $Q_{-i}$. For example, this is implicit in any analysis studying the effects of entry with a Cournot model, where $v \equiv 0$.

REMARK Note that because the vertical merger affects fringe firms only through $Q_{-f}^{*}$, nothing in the proof of result depends on the merger being "vertical". Hence, Proposition 4.3 also applies to horizontal mergers, thus extending Farrel and Shapiro's (1990) analysis of horizontal mergers to the case with free entry.

REMARK This long-run relation is consistent with prices falling and output increasing when the number of firms exogenously increases, which is the standard result in the literature. But adding a zero-profit condition at the margin shows that when prices fall in response to entry, firms at the margin no longer pay their long-run costs and eventually some of them must exit. Provided that

\footnotetext{
${ }^{11}$ Of course, the less intense competition, the higher the long-run price-marginal cost margin.
} 
there is a fringe of similar firms at the margin, firms exit until the price returns to its long-run level.

REMARK Expression (4.3) indicates that the long-run equilibrium price is not invariant to parametric changes that affect function $p^{\prime}$. For example, if market size increases, $\left|p^{\prime}\right|$ and long-run equilibrium margins will fall, a standard result in the literature and also in our model.

To end this section, note that because consumers and firms do exactly as before the merger, the change in welfare is equal to the increase in the affiliate's profits. We can now summarize results with the following corollary:

Corollary 4.4. If there is free entry, then in the long-run vertical integration: (i) does not affect the equilibrium price; (ii) affects neither profits nor outputs of infra marginal firms; (iii) causes exit of fringe firms; (iv) unambiguously increases welfare.

\section{Concluding remarks}

The main conclusion of this paper is that a vertical merger (or any set of vertical restraints that eliminates the externalities between the upstream and the downstream firm), will not by itself confer an "undue" competitive advantage to the merged firm. In most cases vertical integration is either socially beneficial (e.g. in the long-run) or irrelevant (when the downstream market is perfectly competitive). Moreover, when competitors are hurt by the merger, it is because they lose oligopolistic rents.

Our results do not prove that vertical integration is harmless, however. In particular, there is a large literature showing that the vertically integrated bottleneck may have incentives to sab-

otage competitors to recover the market power stemmed by access charge regulation. ${ }^{12}$ Moreover, Vickers' (1995) paper suggests that the access charge $\tau$ fixed by the regulator may change when the bottleneck monopoly vertically integrates. Exploring these incentives to sabotage with the techniques developed in this paper would probably lead to a more comprehensive evaluation of the desirability of vertical integration when the bottleneck monopoly is regulated.

\footnotetext{
${ }^{12}$ For a recent survey see Mandy (2000)
} 


\section{References}

[1] Armstrong, M., C. Doyle and J. Vickers, "The Access Pricing Problem: A Synthesis," Journal of Industrial Economics 44, 131-150, 1996.

[2] Armstrong, M. and J. Vickers, "The Access Pricing Problem with Deregulation: A Note," Journal of Industrial Economics 46, 115-121, 1998.

[3] Biglaiser, G. and P. DeGraba, "Downstream Integration by a Bottleneck Input Supplier Whose Regulated Wholesale Prices are Above Costs," Rand Journal of Economics 32, 137-150, 2001.

[4] Bulow, J., J. Geanakoplos and P. Klemperer, "Multimarket Oligopoly: Strategic Substitutes and Complements," Journal of Political Economy 93, 488-511, 1985.

[5] Bustos A. and A. Galetovic, "Vertical Integration and Sabotage in Regulated Industries," CEA Working Paper Nr. 164, 2003. http://papers.ssrn.com/sol3/papers.cfm?abstract_id=474621

[6] DeGraba, P., "A Bottleneck Input Supplier's Opportunity Cost of Competing Downstream," Journal of Regulatory Economics 13, 287-297, 2003.

[7] Dixit, A., "Comparative Statics for Oligopoly," International Economic Review 27, 107-122, 1986.

[8] Escobar, J. and A. Galetovic, "Dixit's Stability Conditions Imply Uniqueness of Oligopoly Equilibria," mimeo, 2004.

[9] Farrel, J. and C. Shapiro, "Horizontal Mergers: An Equilibrium Analysis," American Economic Review 80, 107-126, 1990.

[10] Kühn, K. and X. Vives, "Excess Entry, Vertical Integration, and Welfare," Rand Journal of Economics 30, 575-603, 1999.

[11] Mandy, Killing the Goose that May Have Laid the Golden Egg: Only the Data Knows whether Sabotage Pays," Journal of Regulatory Economics 17, 157-172, 2000.

[12] Mankiw, G. and M. Whinston, "Free Entry and Social Inefficiency," Rand Journal of Economics 17, 48-58, 1986.

[13] Mathewson, G. and R. Winter, "An Economic Theory of Vertical Restraints," Rand Journal of Economics 15, 27-38, 1984.

[14] Seade, J., "On the Effects of Entry" Econometrica 48, 479-480, 1980.

[15] Seade, J., "Price, Profits and Taxes in Oligopoly," working paper, University of Warwick, 1983.

[16] Vives, X., Oligopoly Pricing: Old Ideas and New Tools. Cambridge: MIT Press, 1999.

[17] Vickers, J., "Competition and Regulation in Vertically Related Markets," Review of Economic Studies 62, 1-17, 1995. 


\section{Table 1 \\ Summary of results}

\begin{tabular}{|c|c|c|}
\hline & Oligopoly & Perfect competition \\
\hline Short run & $\begin{array}{c}\text { - Consumers gain } \\
\text { - Competitors lose } \\
\text { - Monopoly gains } \\
\text { - Welfare generally rises }\end{array}$ & No effect \\
\hline Long run & $\begin{array}{c}\text { - Consumers indifferent } \\
\text { - Competitors indifferent } \\
\text { - Monopoly gains } \\
\text { - Welfare rises }\end{array}$ & No effect \\
\hline
\end{tabular}




\section{Figure 1}

The long-run equilibrium price does not change with a merger

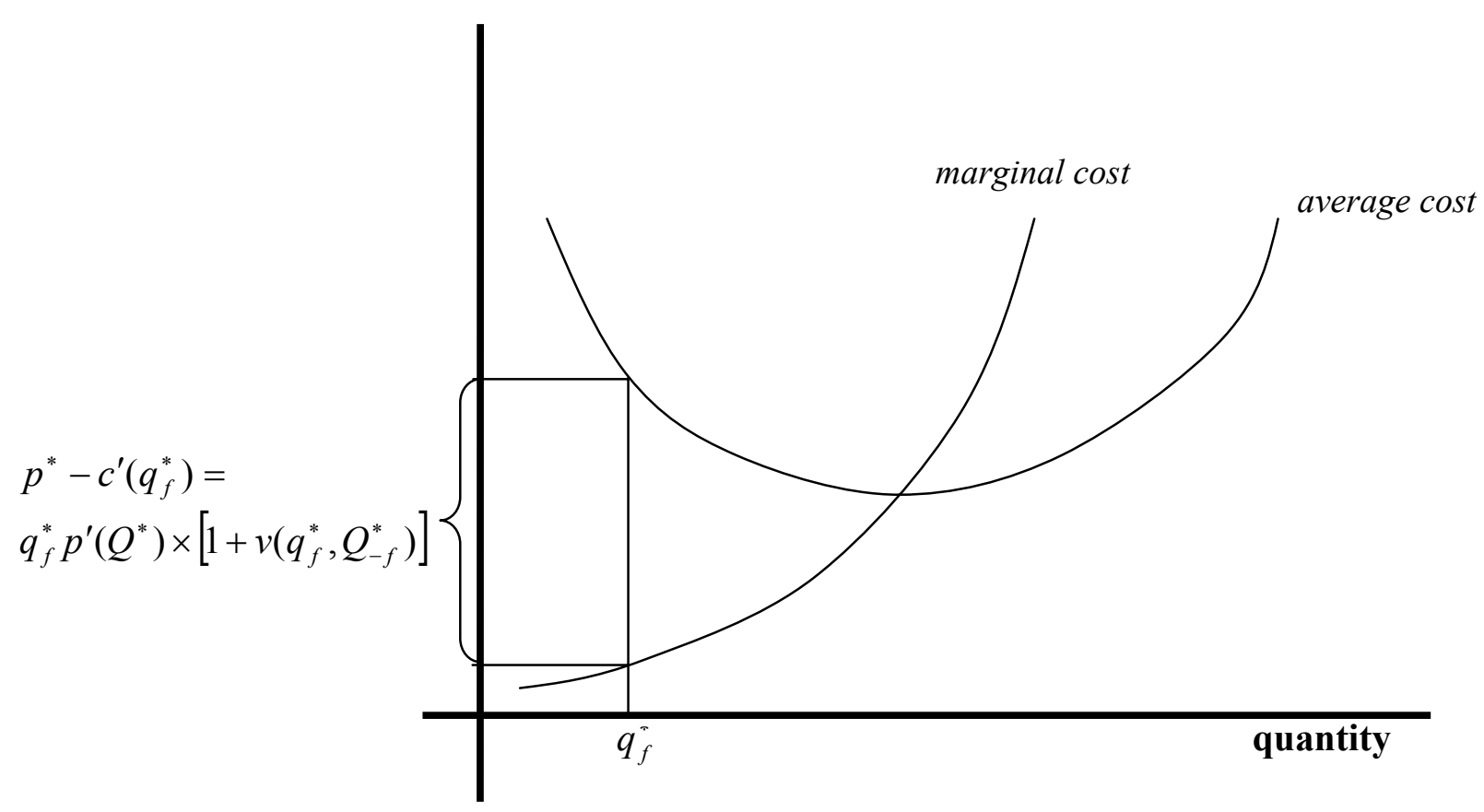

